\title{
The climatic determinants of cotton yields: Evidence from a plot in West Africa
}

\author{
Elodie Blanc $^{a}$, Philippe Quirion ${ }^{a}$, Eric Strobl ${ }^{b, *}$ \\ ${ }^{a}$ CIRED, CNRS, LMD, IPSL, 45 bis avenue de la Belle Gabrielle, 94736 Nogent sur Marne, France \\ ${ }^{\mathrm{b}}$ Department of Economics and SALISES, École Polytechnique, 91128 Palaiseau Cedex, France
}

\section{A R T I C L E I N F O}

Article history:

Received 29 April 2007

Received in revised form

3 February 2008

Accepted 22 February 2008

Keywords:

Cotton

Yields

Climate

West Africa

\begin{abstract}
A B S T R A C T
We conduct a multiple regression analysis of the main climatic determinants of rain fed cotton (Gossypium hirsutum L.) yields for an experimental plot located in Mali, West Africa. The use of daily climatic data allows us to explicitly examine the role of cumulative precipitation, the length of the rainy season, the number of dry spells, the flooding periods, temperature, and solar radiation in determining annual cotton production, and the results of our analysis confirms their importance. In general our findings are in line with the current agronomic literature.
\end{abstract}

(C) 2008 Elsevier B.V. All rights reserved.

\section{Introduction}

In West Africa climatic variations are often mentioned by peasants as the major risk factor of agricultural production (Ingram et al., 2002) and this has been confirmed by a number of studies (Romuald-Robert and Bouchy, 1965; Sivakumar, 1988; Kangah, 2004; Motha et al., 2006; Stern et al., 2006). However, although there are a number of agricultural studies that have shown the importance of climate and meteorology for the yields of the main agricultural crops in Africa (Sultan et al., 2005), there are few which have explicitly examined cotton crop production, despite its primary economic importance for West African francophone countries (Bichat, 2006). Moreover, the few statistical analysis on cotton production in West Africa that have been conducted do not always find evidence of the importance of climatic conditions.

One likely reason for the lack of clear conclusions about the effect of climate and meteorology on cotton yields in West
Africa for the few existing studies is that these mainly rely on monthly (and not daily) climatic data. Since non-daily data by definition consist of averages and totals over a rather long period, they arguably do not allow the researcher to accurately take account of climate related features and the possibility that their impact may depend on the phenological stage of the plant. Indeed, analyses with the use of non-daily data excludes the possibility of considering the length of the rainy season, the flooding periods, and dry spell occurrences, the importance of which has, for example, been demonstrated in the case of millet (Panicum miliaceum L.).

In this article, we conduct an multiple regression analysis of the main climatic determinants of rain fed cotton yields. In this regard we resort to the use of daily climatic and yearly yields data collected from an experimental plot located in the region of Koutiala, south Mali. More precisely, the experimental plot was situated in the typical West African cotton production area, i.e., between the 600 and $1300 \mathrm{~mm}$ isohyets

\footnotetext{
* Corresponding author. Tel.: +33 1693326 47; fax: +3316933 3858.

E-mail address: eric.strobl@shs.polytechnique.fr (E. Strobl). 
(OECD Sahel and West Africa Club Secretariat, 2005) of the Soudano-Sahelian belt which is characterized by two contrasting seasons-a rainy season that stretches from June to October and a dry season that takes place from November to May. It should be noted that this experiment, the primary purpose of which was to allow an examination of the evolution of fertility under a multiple-crops (including cotton) rotation, has been chosen in view of explicitly recreating a setting representative of Soudano-Sahelian climatic conditions of cotton cropping.

The remainder of this paper is organised as follows. In the following section we outline the main climatic factors that are arguably important for cotton production. Our data set is described in Section 3. Section 4 contains the multiple regression models and results. Concluding remarks are provided in the final section.

\section{The role of climate in cotton production}

There are arguably three main sets of climatic features that are potentially important in cotton production: rainfall, humidity and temperature, and solar radiation. We outline their perceived role in cotton production below.

\subsection{Rainfall}

Rain-fed cropping, being non-irrigated, relies exclusively on local rainfall characteristics. Importantly, rainfall has to be in sufficient quantity, but also at a period and at a pace adequate to the vegetative cycle of the plant (David, 1971). The quality of the rainy season is indeed determined by several parameters: its duration, which depends on the onset and cessation dates of the monsoon, its distribution, and its variability (Kangah, 2004). With regard to the latter, the inter-annual variation of rainfall is given by the difference between the cumulative amounts of rain over a certain period in a given area. The temporal analysis led by Kangah (2004, pp. 185-187), based on intra-national (counties or department) data, provides an estimation of the relationship between rainfall variations in West Africa and its impact on crops in terms of yields. More specifically, the variation of rain appears to be the dominant constraint on agricultural productivity in Mali, Burkina Faso and Ivory Coast. Nevertheless, depending on the crop considered, the aforementioned study discovered different reactions in production to rainfall variation. In contrast, Albergel et al. (1985)'s statistical analysis shows a positive link between precipitation and the variation of cotton production in Burkina Faso. They found significant positive coefficients of correlation of 0.72 for the whole cotton zone and 0.67 for the most intensive area of production. In terms of yields, BellaMedjo et al. (2005)'s analysis of precipitation in the north of Cameroon revealed a positive and significant correlation coefficient of 0.59 . However, the authors emphasize that these results correspond to the northern zone of the country only, that is to say where the annual amounts of rain are below $600 \mathrm{~mm}$. For the southern zone, where rainfall exceeds $600 \mathrm{~mm}$ per annum, no significant results were found. This suggests the possible existence of a threshold in the link between precipitations and cotton yields.
It is important, however, to highlight an important limitation with regard to the findings of the studies just outlined. In particularly, these studies rely on simple correlation analysis, but feasibly other parameters may play an important role, thus biasing the results. For example, experiments on a cotton plot in Senegal provided high yields even though the rain was insufficient (Milleville, 1976), but, according to the author, "it is necessary to underline that if a deficit of rain has a negative impact on the satisfaction of the plant water needs, it represents in counterpart and indirectly, some favourable effects: increase of solar radiations, reduction of weeds and parasitism". It is thus clearly important to extend the existing studies using multiple regression analyses, controlling for other potentially important variables.

An important factor of rainfall to also consider is the length of the rainy season as it will condition the length of the cultural season and hence the development potential of plants. As noted by Dounias et al. (2002), the productive potential of the cotton plant will depend on the length of its development cycle, where higher yields should be associated with a longer cropping season. In this regard, Kangah (2004, pp. 201-213) tested the correlation between yields and the monsoon's onset and cessation dates for different crops and at the intranational scale. For each one of the 10 regions considered, a late cessation date was found to be negatively, and mostly significantly, correlated with the cotton yields. Of interest is also that, in most cases, a late onset of the rainy season was significantly linked to higher yields, although the author does not provide any results concerning the relationship between yields and the length of the rainy season.

One also needs to take into consideration the period during which no rain falls, i.e., a dry spell. The identification of such periods is done via the counting of consecutive dry days, where a day is considered to be dry when less than $1 \mathrm{~mm}$ of water falls (Stern et al., 2006). ${ }^{1}$ The results of simulations done by Sultan et al. (2005) with the agronomic model SARRA-H indicates that dry spells during the monsoon may have an impact on plant yields (here millet). However, the authors specify that the weight of the impact (which can be null) will depend on the phenologic state of the plant at the time of its occurrence. With regard to the current paper, this feature is likely to be particularly important for cotton. More specifically, the cotton plant is especially vulnerable to water stress at two stages of its growth, right after it has been sown and during the blooming phase (Parry, 1982). Importantly, while dry spell occurrences between these two periods may explain lower yields, this possibility has never been studied in the case of cotton.

In contrast to dry spells, flooding periods consist of times when the rainfall exceed the plants' needs. This can lead to a nutrient flush in the soil, but also be damaging for the plant. Indeed, the plant reacts to an excess of water over a short period, i.e., when it falls more than $100 \mathrm{~mm}$ of water in approximately $48 \mathrm{~h}$ (Crétenet, personal interview), by a root anoxia. Reicosky et al. (1985) specifically tried to quantify the impact of flooding on cotton yields. Their study consisted of

\footnotetext{
${ }^{1}$ This same criterion is used by the regional centre Agrhymet to identify the dry spell in their data base (Centre Regional Agrhymet, 2002).
} 
the observation of two flooding periods: the first preceding the blooming (82 days after the sowing) and the second before the bowl opening (131 days after the sowing), where these periods correspond to the phenological stages where the need of water is less important. ${ }^{2}$ This study also showed a reduced growth of leaves and their wilt after the first session of flooding, but the effects of the latest session are less important since they only entail a reduced growth of the leaves. The effects on yields are, according to the authors, the consequence of a nutrient flush more than of water stress. However, the flooding periods can have a direct impact on the plant if they appear at the blooming stage. It is thus imperative that the rain stops at the bowl opening phase in order to prevent their rotting (RomualdRobert and Bouchy, 1965). An excess of rain is therefore a limiting factor of cotton plant growth even if the extent of the impact will depend on the phenological stage. In general, in order to ensure good development, it is thus imperative that precipitation is stretched enough over the season (RomualdRobert and Bouchy, 1965). Extreme events, such as inundations or droughts, can clearly have detrimental negative effects on the productive potential.

\subsection{Humidity and temperature}

Humidity and temperature can have an influence on cotton yields either directly by impeding plant growth, or, indirectly through the creation of conditions favourable for parasitism and diseases (Stern et al., 2006), where the origins of such diseases can be of a fungous, organic, viral, or bacterial nature (David, 1971). Considering the direct impact, and especially those regarding to temperature, it has been established that the cotton plant requires a considerable level of heat, somewhere between 25 and $35^{\circ} \mathrm{C}$ during 150 days (CIRAD, 2006). Similarly Lagandre (2005) estimates a warmness requirement of at least $1450 \mathrm{DD}$ (degree days). ${ }^{3}$ Roussopoulos et al. (1998) found that, " a cotton growing season cooler on average by only $1{ }^{\circ} \mathrm{C}$ will considerably delay maturity". Reddy et al. (1995) experiments of cotton cultivation off site ${ }^{4}$ displayed an influence of temperature on the cotton plant development. More specifically, they found a positive relationship between the plant's height, the stem elongation rate, the number of bolls and squares and the level of temperature. Roussopoulos et al. (1998) experiments in growth rooms allowed them to estimate a lower threshold temperature of $12{ }^{\circ} \mathrm{C}$. In contrast, excessive warmth, i.e., temperature higher than $38^{\circ} \mathrm{C}$, may also be damaging for the cotton plant (David, 1971) and limit the seed germination (Arndt, 1945).

Although the cotton plant also needs humidity, an excess of it during the whole vegetative cycle can be damaging (Parry, 1982). David (1971) noted that what the cotton plant requires most of all to ensure adequate growing conditions is a synchronization of both humidity and temperature, since

\footnotetext{
2 This can be verified from Parry's (1982) graph representing the cotton plant water needs established.

3 The degree days is the measurement of the warmness need of a plant. The DD is the daily amount of degrees superior to $16^{\circ} \mathrm{C}$ (useful degrees).

4 The cotton was grown in chambers where temperature and $\mathrm{CO}_{2}$ were controlled.
}

otherwise the humidity rate and the temperature can have indirect negative impacts on cotton yields. As any vegetal, the cotton plant is the target of parasites that can destroy the plant and the bowls (David, 1971). According to Akle and Gaborel (1984), parasite assaults are the most important determining factors of cotton production. More specifically, the authors estimate that without any protection, cotton production is reduced, on average and depending on the season, from 50 to $80 \%$ of its potential. Other experiments, done by the CNRA (2002) on an observational plot in Ivory Coast, allowed the quantification of the impact of parasitism on production and the efficiency of protection programs. More specifically, in 2001 losses in production were found to be $39 \%$, in $200048.5 \%$, in 1999 41.8\% and in 1998 47.4\%. The authors also discovered that the impact of parasitism increased as one moved from North West to South. One should note, however, that while the recognition of these parasite assaults is essential in explaining the variations of production, they are, nevertheless, not always easily identifiable. ${ }^{5}$ Thus the rate of humidity and the temperature may serve as the only feasible proxies in most cases.

\subsection{Solar radiation}

The cotton plant has a fundamental need for sun, implying that a decrease in solar radiation will have immediate consequences for yields (Lagandre, 2005). More precisely, the duration of sun shine positively influences the photosynthetic conversion, ${ }^{6}$ whereas the radiation intensity favours evapotranspiration. ${ }^{7}$ Solar radiation consists of a combination of these two parameters. In this regard, Corcelle (1950) observed a positive relationship between the daily frequencies of flowering of cotton plant, and the solar radiation level 3 days before. The plant reacts by a riddance of the bowls in case of a lack of water and nutrients.

\section{Data and summary statistics}

The analysis undertaken here is based on data from longterm trials conducted by IER/SRCFJ ${ }^{8}$ from 1965 to 1990 on a cultivation area located in the region of Koutiala in Mali (Crétenet et al., 1994; Jardot, 1988). As reported by Kaya and Nair, the soil type of this area is classified as Typic Plinthustalf and has a sandy loam texture of the top $30 \mathrm{~cm}$ becoming finer textured at depths of $50-100 \mathrm{~cm}$. According to the authors, the soil "is highly leached, has distinct horizons underlaid with hard pans rich in iron oxides, is poor in nutrient stores and low in organic matter, and is highly prone to severe sheet erosion". A series of three trials were conducted, at first with a

\footnotetext{
${ }^{5}$ Their detection would require a specific and very close scrutiny.

${ }^{6}$ The photosynthesis is the fabrication of organic matter from mineral matter in the presence of light.

7 The evapotranspiration correspond to the total quantity of water transferred from the soil to the atmosphere trough evaporation at the soil level and from plants transpirations.

${ }^{8}$ Section Recherche Cotonnière et Fibre Jutière de l'Institut d'Economie Rurale.
} 
quadrennial rotation of the crops (cotton-sorgho-groundnut-sorgho), and from 1976 onwards with a triennial rotation (groundnut-cotton-sorgho). ${ }^{9}$ One should note that, because of the change of rotation, 3 years of cotton yields measurements are missing (1968, 1972 and 1975).

Three kinds of fertilization were used on the plots: organic manure, mineral manure, and a combination of both types. In this study we only consider the yields of cotton from plots where the organic and mineral combination of manure was applied. Indeed, as demonstrated by Crétenet et al. (1994), it is this fertilization method that allows the best production results. More precisely, the organic manure favours the water retention and provides potassium, while the mineral manure brings nitrogen and phosphorus. By only considering the yields of plots receiving this combination of fertilization types, we are thus closest to yield potential, that is to say to maximum yields achievable. These 'ideal' cultivation conditions arguably allow abstracting from the analysis of any other influences that are not climate related.

The corresponding climatic data are provided by the agrobio-climatologic station of N'Tarla (latitude: $12^{\circ} 75^{\prime}$; longitude: $-5^{\circ} 75^{\prime}$; elevation: $304 \mathrm{~m}$ ). More specifically, the climatic data available on the experimental zone of N'Tarla are given for each day in terms of (a) pluviometry, (b) maximal temperature, (c) minimal temperature, (d) solar radiation, and (e) wind intensity. For each year we also know the sowing date of cotton. One may want to also note that neither parasitism nor weed pressure are represented in the dataset since these both were eradicated during the experiments on the plots.

The available data allow us to generate many variables that, in accordance with our outline of the likely important climatic variables, could potentially have had an impact on the yields. First of all, it allows one to determine the periods over which these variables are to be considered: the rainy season or the cultural season. The length of the rainy season is the difference between the onset and the cessation of the rainy season. Sivakumar (1988) noted that to determine the onset date different criterions exist and that these will depend on the kind of plant being considered. For the case of cotton Crétenet (personal interview) argues that it is generally agreed that one should link the beginning of the rainy season with the mineralization peak of the organic matter of the soil (nitrogen flush particularly important), which, according to the experiments led by J. Ekorong at Moute in Cameroon, is initiated with the rainfall aggregate of $50 \mathrm{~mm}$. To determine the cessation date, the said author takes the rainfall aggregate corresponding to $90 \%$ of the total rainfall of the year, although one should note that this criterion for the end of the season has no particular agronomic justification.

Most of the climatic variables derived from our data are considered for the length of the cultural season, i.e., solely on the period where it is useful to the plant. We define the cultural season duration (in number of days) as the difference between the sowing date and the end of the rainy season. The daily rainfall data enabled us to calculate the number of dry spell occurrences which, as suggest by Sultan et al. (2005), are likely to have an impact on agricultural output. Therefore, we

${ }^{9}$ The same cultivars were used all along the trials. identified it by the number of periods where precipitation was less than $1 \mathrm{~mm}$ (Stern et al., 2006). The daily data are of particular importance in this regard since they allow one to distinguish between dry spells of different lengths. In order to consider their impact when the cotton plant is more vulnerable to water stress, we considered the dry spells occurring right after it has been sown and during the blooming phase as explained by Parry (1982). We also considered the same three different minimal dry spell's length of 7, 8 and 9 days. To assess the impact of an excess of water, we have checked for the occurrence of flooding periods (the variable takes on the value 1) or not (the variable takes on the value 0 ). As suggested by Crétenet (personal interview), we have done so for a cumulative precipitation of at least $100 \mathrm{~mm}$ of water in approximately $48 \mathrm{~h}$. But, we also considered lower thresholds of 80 and $90 \mathrm{~mm}$ in $48 \mathrm{~h}$.

The cotton plant radiation requirements (Lagandre, 2005; Corcelle, 1950) are assessed here by the solar radiations (given in $\mathrm{Rg} \mathrm{MJ} / \mathrm{m}^{2}$ ). The minimum and maximum temperatures $\left({ }^{\circ} \mathrm{C}\right)$ allow one to calculate the average temperatures. The daily maximum temperature data also enables one to assess the impact of high temperatures which, according to David (1971), may be damaging to the plant when it exceeds $38^{\circ} \mathrm{C}$. We thus counted the days where the maximum temperatures was at least $38^{\circ} \mathrm{C}$, as well as when it was at least $38^{\circ} \mathrm{C}$. Finally, the precipitation data allows one to calculate the total amount of rain. This parameter is considered over the rainfall season rather than the cultural season, thereby taking into account the constitution of water savings in the soil preceding the sowing.

We report summary statistics of all our variables in Table 1 . As can be seen, the yields are highly variable, with a standard deviation of some $560 \mathrm{~kg} \mathrm{ha}^{-1}$. In contrast, cumulative rainfall is considerably less dispersed with the standard deviation being only a fraction of its mean. Nevertheless, one may want to note that the number of dry spells displays considerable variability. Indeed, the occurrence of those of at least 7 days reached a maximum of 12 periods (that is to say 84 days) within the cultural season, the maximum of which is 144 days. Otherwise, the number of days of extreme warmth over the cultural season are rather rare with an average of around 2 days when one considers the threshold of $38^{\circ} \mathrm{C}$ and less than 1 day when one consider the threshold of 39 and $40^{\circ} \mathrm{C}$.

\section{Statistical analysis}

The main purpose of this paper is to assess the impact of climatic parameters on cotton yield levels. More specifically, we model cotton yields on the experimental plots over the period 1965-1990, except for the years 1968, 1972, and 1975, with the following empirical model:

Yields $\mathrm{t}_{\mathrm{t}}=\alpha+\sum_{\mathrm{i}=1}^{m} \beta_{\mathrm{i}} \mathrm{X}_{\mathrm{t}}^{\mathrm{i}}+\varepsilon_{\mathrm{t}}$

where Yields are the seed cotton yields (seeds and fibre in $\mathrm{kg}$ per hectare), $\mathrm{X}$ a vector of climatic control variables, $\varepsilon$ a gaussian error term, and $\beta$ is the vector of coefficients of 
Table 1 - Descriptive statistics

\begin{tabular}{|c|c|c|c|c|c|}
\hline Variables & Obs. & Average & S.D. & Minimum & Maximum \\
\hline Yields $\left(\mathrm{kg} \mathrm{ha}^{-1}\right)$ & 23 & 2231.738 & 562.2223 & 1241.75 & 2959.25 \\
\hline Cultural season duration (days) & 23 & 118.4783 & 14.22824 & 91 & 144 \\
\hline Dry spells $\geq 7$ days (nbr) & 23 & 5.086957 & 3.073539 & 1 & 12 \\
\hline Dry spells $\geq 8$ days (nbr) & 23 & 3.347826 & 2.186918 & 0 & 8 \\
\hline Dry spells $\geq 9$ days (nbr) & 23 & 2.73913 & 2.453521 & 0 & 8 \\
\hline Dry spells at critical phenological stage $\geq 7$ days (nbr) & 23 & 1.956522 & 1.894448 & 0 & 6 \\
\hline Dry spells at critical phenological stage $\geq 8$ days (nbr) & 23 & 0.869565 & 0.868873 & 0 & 2 \\
\hline Dry spells at critical phenological stage $\geq 9$ days (nbr) & 23 & 0.565217 & 0.589768 & 0 & 2 \\
\hline Flooding periods $\geq 80 \mathrm{~mm}$ in $48 \mathrm{~h}$ (bool.) & 23 & 0.304348 & 0.470472 & 0 & 1 \\
\hline Flooding periods $\geq 90 \mathrm{~mm}$ in $48 \mathrm{~h}$ (bool.) & 23 & 0.173913 & 0.387553 & 0 & 1 \\
\hline Flooding periods $\geq 100 \mathrm{~mm}$ in $48 \mathrm{~h}$ (bool.) & 23 & 0.130435 & 0.344350 & 0 & 1 \\
\hline Rainfall aggregate (mm) & 23 & 727.5652 & 179.6855 & 446 & 1187 \\
\hline Solar radiations $\left(\mathrm{Rg} \mathrm{MJ} / \mathrm{m}^{2}\right)$ & 23 & 20.84429 & 1.192644 & 18.4134 & 22.8484 \\
\hline Degree days & 23 & 1468.304 & 231.1738 & 1120 & 1918 \\
\hline Temperatures average $\left({ }^{\circ} \mathrm{C}\right)$ & 23 & 28.43860 & .8053582 & 26.74657 & 29.68153 \\
\hline Maximal temperatures average $\left({ }^{\circ} \mathrm{C}\right)$ & 23 & 34.16351 & 0.804790 & 32.2805 & 35.5593 \\
\hline Temperatures $\geq 38^{\circ} \mathrm{C}$ (nbr of days) & 23 & 2.043478 & 2.754802 & 0 & 9 \\
\hline Temperatures $\geq 39^{\circ} \mathrm{C}$ (nbr of days) & 23 & 0.826087 & 1.370208 & 0 & 5 \\
\hline Temperatures $\geq 40^{\circ} \mathrm{C}$ (nbr of days) & 23 & 0.260869 & 0.5408236 & 0 & 2 \\
\hline
\end{tabular}

interest. All parameters were estimated using standard ordinary least squares. ${ }^{10} \mathrm{We}$ also verified that our dependent variable was stationary by using a number of Dickey-Fuller unit root tests and found no evidence contrary to this assumption.

Before proceeding to the results, it is important to emphasize that our choice of regressors was dictated by what was deemed important from the literature review in Section 2, what was available in the data, and by keeping the number of explanatory variables to its necessary minimum, since a greater number would have put considerable strain on the degrees of freedom of our estimation, given our small sample size. Thus, the procedure of variable selection consisted of testing all the different combinations of the 18 potential explanatory variables, while avoiding the simultaneous inclusion of the different thresholds concerning the dry spell, flooding, and temperature variables. For those multi-threshold variables, we tested at first the factors at the levels mentioned in the literature review and then proceeded to test them at other levels. In terms of comparing and selecting between different models we used the corrected Akaike Information Criterion (AICc). ${ }^{11}$ Finally, one may want to note that our construction of potential was made independently of the yield values.

The results of all our regressions are given in Table 2. First of all one should note that regardless of our choice of explanatory variables, our empirical model achieves a relatively high explanatory power of the cotton yields, with an R-squared ranging between 85.29 and $93.90 \%$. Additionally, according to the F-test statistics, the hypothesis that all coefficients are jointly zero can be decisively rejected in all model. Finally, from the corrected AIC statistic one can see

\footnotetext{
${ }^{10}$ Another interesting alternative approach would have been to apply a agrophysiological model such as CROPWAT. Unfortunately our data set does not provide us with the necessary parameters to run such a model.

${ }^{11}$ The corrected AIC is here preferred to the AIC criterion for it corrects for small sample size.
}

that the last model is the most preferred, since its coefficient is the smallest.

Concerning the dry spell occurrence, as no particular threshold has been suggested in our literature review, the 8 days level was used as the benchmark value. As it appeared to be non-significant, a higher threshold of 9 days was then tested in the second model but remained insignificant. A significant impact was only discovered when we used a 7day level threshold (Model 3), and this suggested a negative relationship to yields. It is thus likely to be detrimental for cotton plant growth, entailing reduced yields. Our results fail to exhibit a statistically significant impact of dry spells at critical phenological stages, i.e., when the plant water requirements are expected to be the most important.

With regard to the flooding factor, the threshold of $100 \mathrm{~mm}$ of water in $48 \mathrm{~h}$ suggested by Crétenet (personal interview) in Section 2 was included as the benchmark value. Since this variable was insignificant, we experimented with a series of different level threshold values as can be seen in the two subsequent models. This produced a significant (negative) threshold reaction of $90 \mathrm{~mm}$, which is just slightly under the suggested level of $100 \mathrm{~mm}$.

As for temperature, we first considered the level mentioned by David (1971). However, we found no evidence that the number of days where the temperature rises above $38{ }^{\circ} \mathrm{C}$ is a significant factor in cotton production. Even the 39 and $40^{\circ} \mathrm{C}$ thresholds included subsequently failed to reflect the damaging effect of an excessive warmness. This does not seem surprising when one consider the rather limited occurrence of such extreme temperatures as shown in Table 1. However, we found in Model 4 a significant positive impact of the maximum temperatures which reflects the plant requirement of warmth. This result is to some extent confirmed by the lack of evidence concerning the average temperatures or the useful degrees represented by the degree days. The minimum temperature was not considered here since the observed temperatures in our experimental plots were never low enough $\left(<12{ }^{\circ} \mathrm{C}\right)$ to be detrimental for the plant. 
Table 2 - Ordinary least squares regression estimates: cotton yields

\begin{tabular}{|c|c|c|c|c|c|}
\hline & Model 1 & Model 2 & Model 3 & Model 4 & Model 5 \\
\hline $\begin{array}{l}\text { Cultural season duration } \\
\text { Cultural season duration }\end{array}$ & $19.0614^{* *}(7.2319)$ & $25.8304^{*}(6.0061)$ & $23.9863^{*}(5.9285)$ & $22.0154^{*}(3.9474)$ & $\begin{array}{l}149.7733^{*}(39.2793) \\
-0.5408^{*}(0.1657)\end{array}$ \\
\hline Dry spells $\geq 7$ days & & & $-23.4761(17.7621)$ & $-40.4815^{* *}(18.4017)$ & $-37.6364^{* *}(14.5609)$ \\
\hline Dry spells $\geq 8$ days & $-20.8579(29.5862)$ & & & & \\
\hline Dry spells $\geq 9$ days & & 7.9635 (31.6338) & & & \\
\hline Dry spells $\geq 7$ days at critical phenological stage & & & $-7.2581(44.3927)$ & & \\
\hline Dry spells $\geq 8$ days at critical phenological stage & $-7.3228(96.9719)$ & & & & \\
\hline Dry spells $\geq 9$ days at critical phenological stage & & -76.8585 (183.2278) & & & \\
\hline Flooding periods $\geq 80 \mathrm{~mm}$ in $48 \mathrm{~h}$ & & -196.7869 (154.1552) & & & \\
\hline Flooding periods $\geq 90 \mathrm{~mm}$ in $48 \mathrm{~h}$ & & & $-356.6631 \dagger(186.7601)$ & $-253.8461(160.9564)$ & $-376.7228^{* *}(132.5931)$ \\
\hline Flooding periods $\geq 100 \mathrm{~mm}$ in $48 \mathrm{~h}$ & $-492.2761(307.1458)$ & & & & \\
\hline \multicolumn{6}{|l|}{ Flooding periods $\geq 110 \mathrm{~mm}$ in $48 \mathrm{~h}$} \\
\hline Rainfall aggregate & $1.6060^{* *}(0.7296)$ & $0.9377 \dagger(0.5277)$ & $1.0645^{* *}(0.4752)$ & $1.3562^{2 *}(0.4652)$ & $1.5193^{*}(0.3708)$ \\
\hline Solar radiations & $262.5943^{*}(78.6171)$ & $201.1488^{*}(61.5754)$ & $200.0538^{*}(49.7812)$ & $256.8882^{*}(56.4682)$ & $239.5452^{*}(44.9174)$ \\
\hline Degree days & & $-0.2604(0.4687)$ & & & \\
\hline \multicolumn{6}{|l|}{ Wind } \\
\hline Temperatures average & 95.8936 (141.5439) & & & & \\
\hline Maximal temperatures average & & & & $234.1690^{\dagger}(122.8609)$ & $262.7968^{* *}(97.4384)$ \\
\hline Temperatures $\geq 38^{\circ} \mathrm{C}$ & 41.3721 (26.7889) & & & & \\
\hline Temperatures $\geq 39^{\circ} \mathrm{C}$ & & 73.4128 (46.7672) & & & \\
\hline Temperatures $\geq 40^{\circ} \mathrm{C}$ & & & $116.1632(116.0535)$ & & \\
\hline Constant & $-9339.8837 \dagger(5291.7245)$ & $-5300.3064^{*}(1453.5007)$ & $-5389.1780^{*}(1128.3203)$ & $-14467.9153^{* *}(5007.4305)$ & $-22637.1347^{*}(4681.0057)$ \\
\hline$R^{2}$ & 0.8705 & 0.8736 & 0.8801 & 0.8957 & 0.9390 \\
\hline F-test & 11.77 & 12.09 & 15.72 & 22.91 & 32.99 \\
\hline AICc & 340.3422 & 339.7971 & 333.0254 & 324.9875 & 317.4706 \\
\hline
\end{tabular}




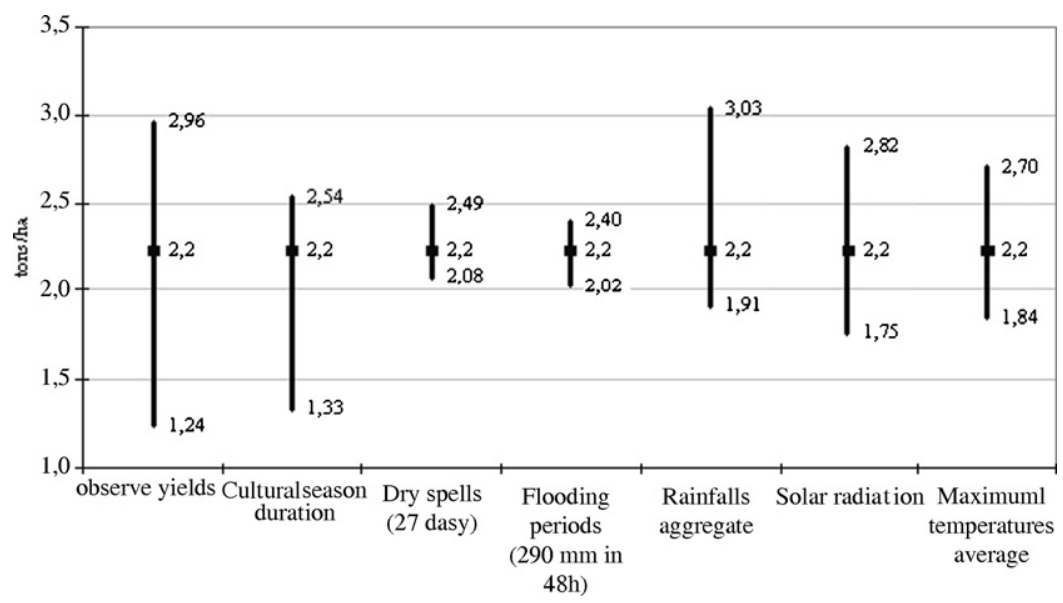

Fig. 1 - Amplitude of observed yields (left bar) and yields simulated by the model (other bars).

The result of the variable selection procedure is given in Model 4 of Table 2. One finds a positive and significant coefficient on the cultural season length, confirming what has already been argued by Dounias et al. (2002), that is to say that the greater the length of this season, the higher cotton production will be. The analysis suggests that cumulative rainfall and solar radiations are also increasing factors of cotton yields.

So far, we have implicitly assumed that all climatic factors can only have a linear on cotton production by only including their levels. Non-linear effects may also potentially exist and therefore we introduced second order terms for all variables except for the flooding periods, since it is of Boolean type. The results of re-estimating this model excluding the nonsignificant squared terms and including the squared term of the cultural season is given in the final model (Model 5). We found that for cultural seasons both the levels and the second order term are significant, whereas the higher order terms for all other controls are not only themselves insignificant but also render the levels values insignificant. This suggests that for this latter set of controls there appears to be no non-linear effect on cotton production, at least as modelled by a second order term. With regards to the second order term on cultural seasons, one should note that the negative coefficient in conjunction with the positive effect of the levels terms suggests that the response curve of yields to the duration of the cultural season is concave, thus indicating the existence of a saturation level of the variable's marginal effect on cotton yields. As a matter of fact, the values of the two coefficients allow us to identify the optimum level before reversal of the positive impact of the length of the cultural season, which corresponds to 148 days. One should note, however, that this threshold is never reached within the observed values in the data set (the maximum of which is 144 days).

Thus far, we have only been able to say something with regard to the statistical significance of our explanatory variables on cotton yield. It is of course also important to assess their economic importance in terms of how important they are quantitatively for cotton production. As a rough guidance in this regard we used the estimated coefficient and the range of values of each explanatory variable to calculate how much of cotton yields they can potentially explain. More precisely, we calculate for the final model (Model 4) the estimated impact of the range (from minimum to maximum) of a particularly variable on yields at the mean impact of the other variables. These various 'explanatory' ranges are depicted in Fig. 1, where the vertical axis shows the predicted impact on yields observed over the 23 years of observation, while along the horizontal axis we graph to the very left the actual yields and then for each control variable the range of cotton yields that can be accounted for by the minimum and maximum values of the control variable in question. The squares situated on each bar indicate the average of observed yields. It turns out that, according to our model, the climatic events that have been the most damageable, everything else being equal, are short cultural season duration and reduced solar radiation. On the contrary, a high solar radiation and cumulative rainfall are the climatic events potentially the more favourable to yields.

\section{Conclusion}

Our study based on daily climatic data and yields observed on a Malian experimental plot (Crétenet et al., 1994) has enabled us to measure the impact of the main climatic factors on rain fed cotton production. Our findings have demonstrated the importance of the use of daily climatic data, as they have allowed us to calculate impact of particular climatic variables, such as the length of the cultural season, the dry spells, and the flooding periods, previously not considered in a multiple regression analysis. In terms of potential future research one should note that, as part of the preparation of the fourth report of the IPCC (Intergovernmental Panel On Climate Change) which is to be published in 2007, the climatologist community will make available for the first time around twenty Global Climate Models simulated climatic scenarios with daily resolutions. ${ }^{12}$ Such climatic hypothetical data would then allow one to use the

\footnotetext{
12 http://www-pcmdi.llnl.gov/ipcc/about_ipcc.php. The model outputs provided by the previous programs of model comparisons were only available at a monthly resolution.
} 
findings of our model in order to estimate the impact of potential climatic change on cotton yields in West Africa.

\section{Acknowledgements}

The authors would like to thank the researchers from the IER and the CIRAD who have contributed to the Malian agronomical experiments from which we derived the data used in this article. We also wish to address a special thank to Dramane Ballo (IER) and Dominique Dureau (CIRAD) whose involvement has been essential to the construction of the database. We also acknowledge Michel Crétenet (CIRAD) for his helpfull comments. Additionally we would like to thank Benjamin Sultan (LOCEAN-IPSL), Jean-Baptiste Butlen (CIRED) and Marion Dewagenaere (CIRED). Finally we are grateful to the Institut Pierre-Simon Laplace (IPSL), which provided the funding for the realisation of this work.

\section{R E F E R E N C E S}

Akle, J., Gaborel, C., 1984. La culture cotonnière au Bénin. Coton et Fibres Tropicales 39 (4), 153-157.

Albergel, J., Carbonnel, J.P., Vaugelade, J., 1985. Aléas climatiques et production agricole: le coton au Burkina. Acta Oecologica-Oecologia Applicata 6 (3), 199-211.

Arndt, C.H., 1945. Temperature-growth relations of the roots and hypocotyls of cotton seedlings. Plant Physiology 20 (2), 200.

Bella-Medjo, M., Sultan, B., Janicot, S., 2005. Analysis of the seasonal cycle of the African monsoon, Regional applications on Cameroon. In: Proceedings of the AMMA 1st International Conference, Dakar, Senegal, 28th November-2nd December.

Bichat, H.-H., 2006. L'or blanc des savanes africaines, Le coton, des futurs à construire. Cahiers/Agricultures 15 (1), 7-8.

Centre Regional Agrhymet, 2002. SGBD AP3A, CD-ROM version 5.2.

CIRAD, 2006. Ce qu'il faut savoir sur le cotonnier et le cotton. Dossier cotton. Centre de Coopération Internationale en Recherche Agronomique pour le Développement.

CNRA, 2002. Bilan 2001. Technical report. Centre National de la Recherche Agronomique Côte d'Ivoire.

Corcelle, P., 1950. Quelques réactions du cotonnier aux influences météorologiques. Coton et Fibres Tropicales 5 (1), $35-40$.

Crétenet, M., Dureau, D., Traore, B., Ballo, D., 1994. Fertilité et fertilisation dans le région sud est du Mali: du diagnostic au pronostic. Agriculture et développement 3, 4-12.
David, J., 1971. Le coton et l'industrie cotonnière, No. 90. Collection Que sais-je? Presses Universitaires de France, Paris.

Dounias, I., Aubry, C., Capillon, A., 2002. Decision-making processes for crop management on African farms; modelling from a case study of cotton crops in northern Cameroon. Agricultural Systems 73 (3), 233-260.

Ingram, K.T., Roncoli, M.C., Kirshen, P.H., 2002. Opportunities and constraints for farmers of west Africa to use seasonal precipitation forecasts with Burkina Faso as a case study. Agricultural Systems 74 (3), 331-349.

Jardot, D., 1988. Synthèse d'un essai pérenne de fertilisation organo-minérale sur cotonnier sur la station de N'Tartla (Mali). IRCT - CIRAD, non-publié.

Kangah, P., 2004. Rainfall and Agriculture in Central West Africa Since 1930. Ph.D. Thesis. University of Oklahoma.

Lagandre, D., 2005. Le secteur cotonnier en zone franc, entre succès et dépendance. Rapport thématique JUMBO 7. Agence Française de Développement.

Milleville, P., 1976. Comportement technique sur une parcelle de cotonnier au Sénégal. Cahiers ORSTOM 11 (4), 263-275.

Motha, R., Sivakumar, M., Bernardi, M., 2006. Strengthening operational agrometeorological services at the national level. In: Proceedings of the Inter-Regional Workshop, March 22-26, 2004, Manila, Philippines, in Technical Bulletin WAOB-2006-1 and AGM-9, No. 1277, p. 238.

Parry, G., 1982. Le cotonnier et ses produits. Collection Techniques agricoles et productions tropicales, Maisonneuve et Larose, Paris.

Reddy, V.R., Reddy, K.R., Acock, B., 1995. Carbon dioxide and temperature interactions on stem extension, node initiation, and fruiting in cotton. Agriculture, Ecosystems \& Environment 55 (1), 17-28.

Reicosky, D., Meyer, W., Schaefer, N., Sides, R., 1985. Cotton response to short-term water logging imposed with a water-table gradient facility. Agricultural Water Management 10 (2), 127-143.

Romuald-Robert, C., Bouchy, C., 1965. Pluviométrie et culture cotonnière en Côte d'Ivoire. Coton et Fibres Tropicales 20 (3), 407-460.

Roussopoulos, D., Liakatas, A., Whittington, W.J., 1998. Controlled-temperature effects on cotton growth and development. The Journal of Agricultural Science (130), 451-462.

Sivakumar, M., 1988. Predicting rainy season potential from the onset of rains in southern Sahelian and Sudanian climatic zones of West Africa. Agricultural and Forest Meteorology 42, 295-305.

Stern, R., Rijks, D., Dale, I., Knock, J., 2006. INSTAT Climatic Guide. Statistical Services Center, University of Reading.

Sultan, B., Baron, C., Dingkuhn, M., Sarr, B., Janicot, S., 2005. Agricultural impacts of large-scale variability of the West African monsoon. Agricultural and Forest Meteorology 128, 93-110. 